\title{
Investigation of Mechanical Properties of Carbon Nanotubes/High Density Polyethylene Composites Produced by Extrusion Method
}

\author{
By Mustafa Tasyurek ${ }^{*}$ \\ Serafettin Ekinci $i^{\dagger}$ \\ Murat Mirik
}

In this study, mechanical properties of multiwalled carbon nanotubes / high density polyethylene (MWCNT/HDPE) nanocomposite materials produced by method of injection molding have been investigated experimentally. Multi-walled carbon nanotubes (MWCNTs) have been incorporated into a high-density polyethylene (HDPE) matrix using twin screw extrusion and injection technique. High density polyethylene, which was reinforced with different percentages $(1 \%, 3 \%$ and $5 \%)$ of carbon nanotubes, was produced in the form of tensile test bars and then tested. The tensile tests were performed according to ASTM D 638 test standards. The increase in tensile strength as a result of the added carbon nanotube was studied. After the experiments, changes of mechanism at fracture surfaces were examined. Experiments were repeated three times. As a result, it could be inferred that minimum percentage of carbon nanotubes reinforcement should be between $1 \%-3 \%$.

\section{Introduction}

From the second half of the twentieth century, developing petrochemical industry has become one of the central pillars of modern economy, thanks to the wide range of products and applications. Since the discovery of the polymer nanocomposites as a new material group that has superior physical performance, as compared to plastic materials and conventional composites, importance and application of these materials in the plastics industry have been rapidly increasing.

Nowadays, composite materials have got such wide application areas that one can encounter them in almost every aspect of our lives. A composite is known as a material formed by combining two or more materials of either

\footnotetext{
*Research Assistant, Selcuk University, Turkey. ${ }^{\dagger}$ Research Assistant, Selcuk University, Turkey. tPrelector, Cumhuriyet University, Turkey.
} 
same or different features in a macroscopic or nano level in order to obtain a new single material with the better features.

Carbon nanotubes have become highly attractive in formation of composite materials in recent years due to their unusual mechanical, optical, electrical properties, plus their tendency of possessing low density, high specific surface area and high aspect ratio. MWCNTs increase the strength of the composite by transferring their superior properties to matrix. It is for this reason that researchers use the MWCNTs at different percentage proportions, of different lengths and diameters and by subjecting them to various chemical processes in order to reinforce polymers (Miannay, 1998), (Kanagaraj et al., 2007), (Dusunceli and Colak, 2007). The researchers employ thermosets such as epoxy, unsaturated polyester, vinyl ester (Tasyurek and Sepet, 2012), (Tasyurek, 2012), (Battisti et al., 2009), (Seyhan et al., 2007) or thermoplastics such as low density polyethylene, polypropylene and polyamide as suppliments (Jung et al., 2013), (Gandhi, 2013), (Li et al., 2006).

When the MWCNTs are reinforced to polymer, it is primarily checked whether homogeneous distribution is achieved. Also, the interface between matrix material and the reinforcement material is taken into account. On the other hand, cost analysis is carried out because some types of the MWCNTs are very expensive. The high production cost of multi walled carbon nanotubes (MWCNTs) limits their applications as nanofillers for the preparation of polymer nanocomposites (Hooshmand et al., 2011), (Grimmer and Dharan, 2010).

\section{Materials and Methods}

\section{Materials}

In this study, high-density polyethylene was used as matrix material whereas the multi-walled carbon nanotubes acted as reinforcing materials. Properties of the carbon nanotube used in the study are given in table 1. and properties of thermoplastic matrix material are given in table 2. (Mirik, 2010). Also, formula and chemical composition of HDPE are given in figure 1.

Table 1. The Physical Properties of Multi-walled Carbon Nanotube

\begin{tabular}{|c|c|}
\hline Average Diameter & $10-40 \mathrm{~nm}$ \\
\hline Length & $1-25 \mu \mathrm{m}$ \\
\hline Purity & Min. $\% 93$ \\
\hline Specific Surface Area & $150-250 \mathrm{~mm}^{2}$ \\
\hline
\end{tabular}

Table 2. The Properties of High Density Polyethylene

\begin{tabular}{|c|c|}
\hline Melt Flow Rate $(\mathrm{g} / 10 \mathrm{~min})$ & 0.04 \\
\hline Density $\left(\mathrm{kg} / \mathrm{m}^{3}\right)$ & 957.6 \\
\hline Yield Stress $(\mathrm{MPa})$ & 22.555 \\
\hline Tensile Strength at Break $(\mathrm{MPa})$ & 29.420 \\
\hline Elongation at Break $(\%)$ & $>500$ \\
\hline Melting Point $\left({ }^{\circ} \mathrm{C}\right)$ & 131 \\
\hline
\end{tabular}


Figure 1. Formula of HDPE

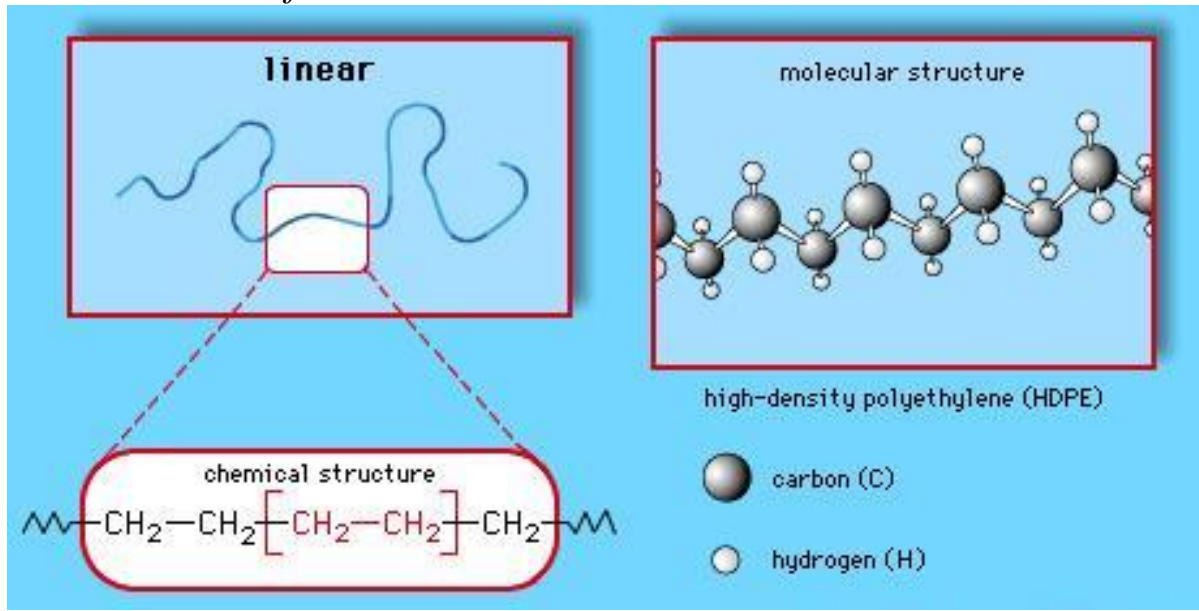

\section{Preparation of Samples}

Multi-walled carbon nanotubes (MWCNTs) at an amount of $1 \% ; 3 \%$ and $5 \%(\mathrm{wt} / \mathrm{wt}$ ) by weight were dispersed in a HDPE matrix using a twin-screw extruder.

Firstly, selected amount of carbon nanotubes and polyethylene were weighed using a $0.001 \mathrm{~g}$ precision electronic balance. Before mixing in the extruder, carbon nanotubes were added into polyethylene powder materials with a double-bladed stirrer rotating at a speed of $525 \mathrm{rev} / \mathrm{min}$. Stirring was maintained at room temperature for $10 \mathrm{~min}$.

Figure 2. Extrusion Process

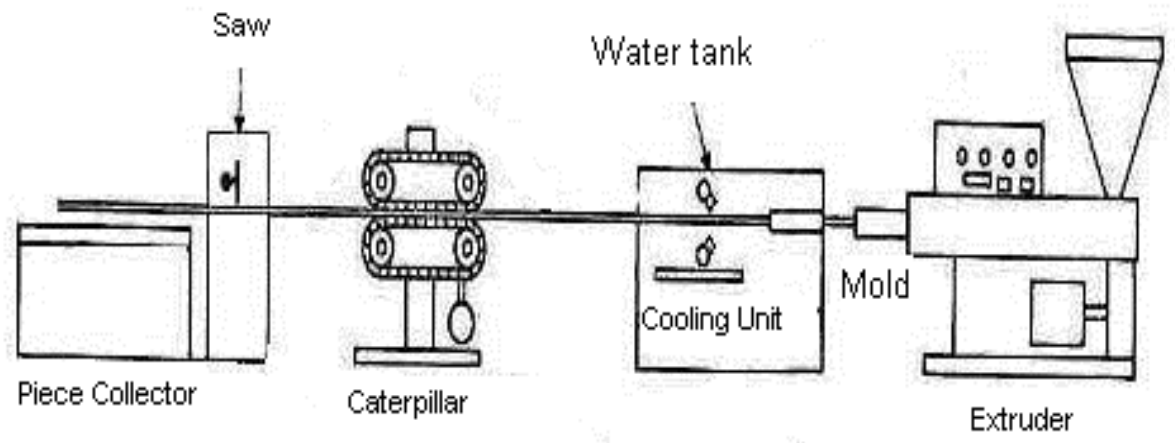

The samples prepared in the extruder in a granular form were obtained through pressing into a mold of an injection molding machine at a pressure of $40 \mathrm{MPa}$ and at temperature of $190{ }^{\circ} \mathrm{C}$. The samples were preheated for 20 seconds and finally cooled at cooling temperature (approximately $40^{\circ} \mathrm{C}$ ) for 30 seconds. Extruder is shown in figure 2. 


\section{Tensile Strength Tests}

Samples were prepared according to standard ASTM D 638. The test specimen is shown in Figure 3. and the sizes of samples are shown in table 3. The crack length was selected according to the sample width. Single edge crack was prepared at the middle part of the sample (without allowing the formation of micro-cracks). Crack has a length of $25 \%, 50 \%$ and $66 \%$ of width of the samples (w).

The central part of the tensile specimens can be considered as a plate. Accordingly; stress intensity factor of single-edge cracked plate under tensile load can be calculated. Stress intensity factor is calculated using the following formula:

$$
K_{l}=\sigma \sqrt{\pi a}\left[1,12-0,23(a / b)+10,6\left((a / b)^{2}\right)-21,7(a / b)^{3}+30,4(a / b)^{4}\right]
$$

Figure 3. Tensile Specimen Dimensions

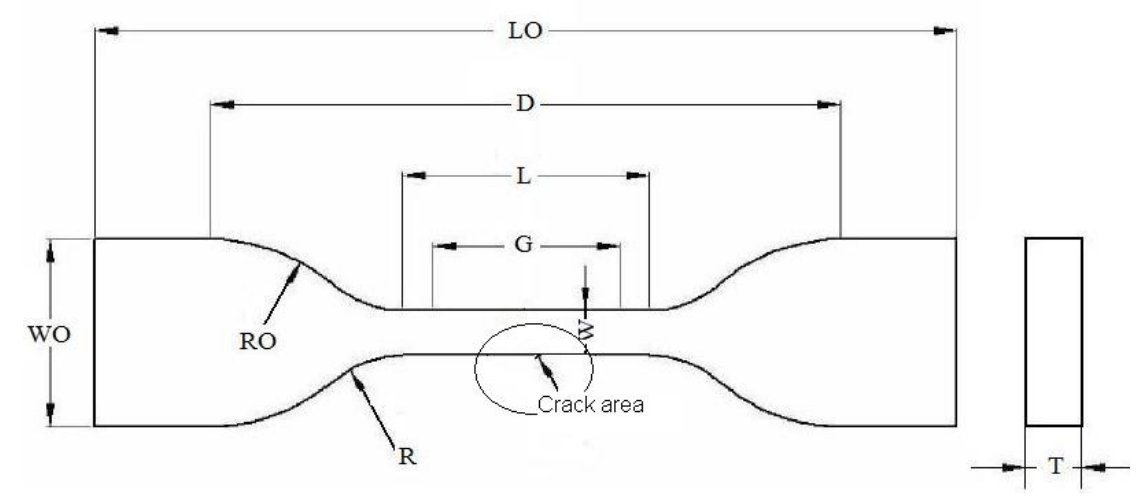

Table 3. Sample Dimensions

\begin{tabular}{|c|c|}
\hline Sample Dimensions & $(\mathrm{mm})$ \\
\hline The width of the narrow region (W) & 6 \\
\hline The length of the narrow region (L) & 33 \\
\hline Full width (W0) & 19 \\
\hline Full size (L0) & 115 \\
\hline Gauge Length(G) & 25 \\
\hline The distance between the ends (D) & 65 \\
\hline Radius (R) & 14 \\
\hline Width (T) & 4.5 \\
\hline Outer radius (R0) & 25 \\
\hline
\end{tabular}

Thermo Gravimetric Analysis (TGA)

In thermogravimetric analysis, changes in the mass of material heated at a suitable speed were measured at electronic precision scales. Sample was heated according to the proper program after sample was measured for its weight in the scale of the TGA device and selection of the nitrogen gas according to the sample specification. After weighing the sample in the TGA balance device, 
depending on the nature of the sample by selecting the appropriate gas, is heated according to suitable temperature program. The proper programme options and temperature conditions are described below:

Generally, temperature is programmed up to $1000^{\circ} \mathrm{C}$ for polymer samples. Heating rate is $10^{\circ} \mathrm{C} / \mathrm{min}$ and gas flow is $50 \mathrm{ml} / \mathrm{min}$ according to the ASTM E 1131 standard. Air is passed at $600{ }^{\circ} \mathrm{C}$ under a nitrogen atmosphere. The amount of change in the sample mass is recorded as a function of time or temperature. Mass loss for the desired temperature range was calculated in $\mathrm{mg}$.

Mass loss due to temperature (TGA) shows the results of mass loss speed (DTG) the first derivative of the mass loss amount.

\section{Results and Discussion}

\section{Tensile Test}

The tensile tests were carried out on a universal testing machine. Tensile speed was set to $5 \mathrm{~mm} / \mathrm{min}$. Three types of specimens were prepared in addition to control samples (traditional HDPE specimens). Percentages of the MWCNT were chosen as $\% 1, \% 3$ and $\%$ 5. All samples were tested to successive and in the same environmental conditions. Also, tests of repetition samples were tested successively and sequentially. All test results are shown in table 4.

Table 4. The Average Tensile Test Results

\begin{tabular}{|c|c|c|c|c|}
\hline & $\begin{array}{c}\text { Max. Force } \\
(\mathrm{N})\end{array}$ & $\begin{array}{c}\text { Ultimate } \\
\text { Tensile } \\
\text { Strength } \\
(\mathrm{MPa})\end{array}$ & $\begin{array}{c}\text { Breaking } \\
\text { Strength (N) }\end{array}$ & $\begin{array}{c}\text { Elongation at } \\
\text { Break (\%) }\end{array}$ \\
\hline HDPE & 467.6 & 19.48 & 281 & 76.6 \\
\hline \% 1 MWCNT & 474.3 & 19.76 & 209.3 & 68.2 \\
\hline \% 3 MWCNT & 500 & 20.83 & 294.3 & 70.05 \\
\hline \% 5 MWCNT & 510 & 21.25 & 167 & 55.3 \\
\hline
\end{tabular}

Also, edge cracks were opened to some of the tensile bars for tensile tests in order to learn how an edge crack probably occurs at structures and components subjected to tension (pulling) effects to tension strength. Edge crack was placed in the middle point of the narrow profile of the sample in the single direction.

The variation of tensile strength for HDPE/MWCNTs nanocomposites for notched and unnotched samples is shown as a function of MWCNTs content in figures 4., 5., 6. and 7. These figures indicate that the tensile strength of the epoxy resin reinforced with MWCNTs improves as MWCNTs content increases. However, $1 \%$ reinforcement ratio it does not provide a considerable increase. The significant increase of tensile strength was observed between MWCNTs 1.0 wt. (\%) - 3.0 wt. (\%). It is obvious that MWCNTs content plays an important role in tensile strength (Jin-Hua et al., 2012). MWCNTs reinforcement generally provides strength improvement. This increase is 
primarily due to homogeneous distribution of MWCNTs in the matrix (Loos et al., 2013). In addition, MWCNTs transfers their individual strength to composite materials via taking over the load applied to the matrix material. MWCNTs prevent the proliferation of cracks in the matrix during stripping situations through their foaming movement. This situation is also supported by the literature (Tasyurek, 2014). However, minimum reinforcement amount can change due to attained strength improvement according to the reinforcement material. But the MWCNTs used in the present study generally give better results at $5 \% \mathrm{wt}$.

Figure 4. The Effect of MWCNT Reinforcement to Maximum Force at Unnotched Samples

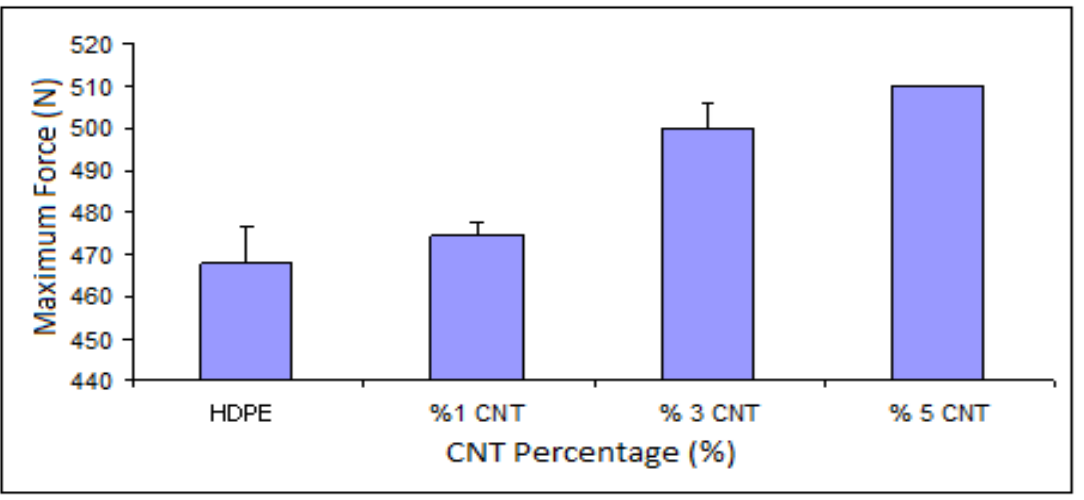

Figure 5. The Effect of MWCNT Reinforcement to Maximum Force at $25 \%$ Notched Samples

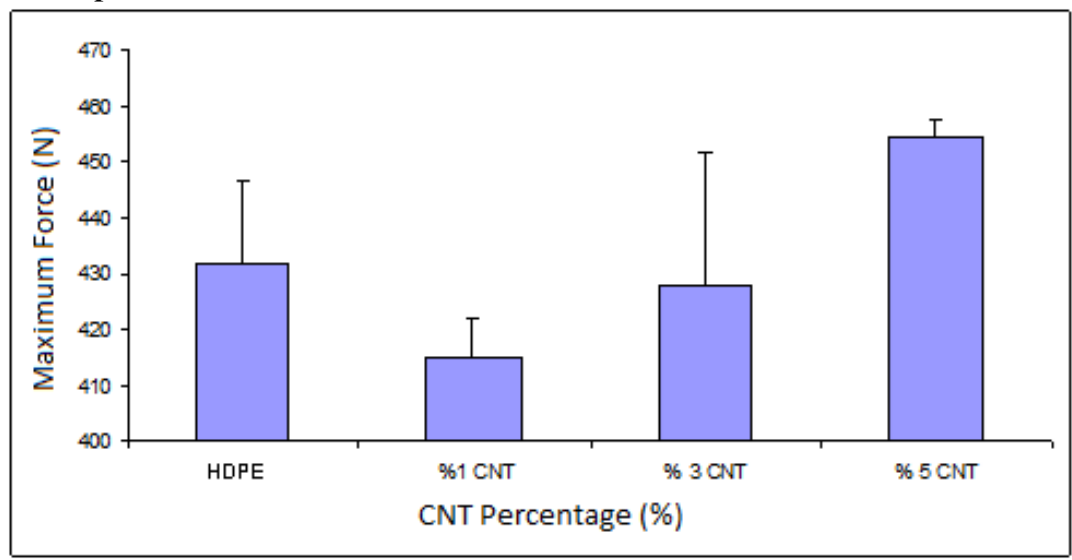


Figure 6. The Effect of MWCNT Reinforcement to Maximum Force at 50\% Notched Samples

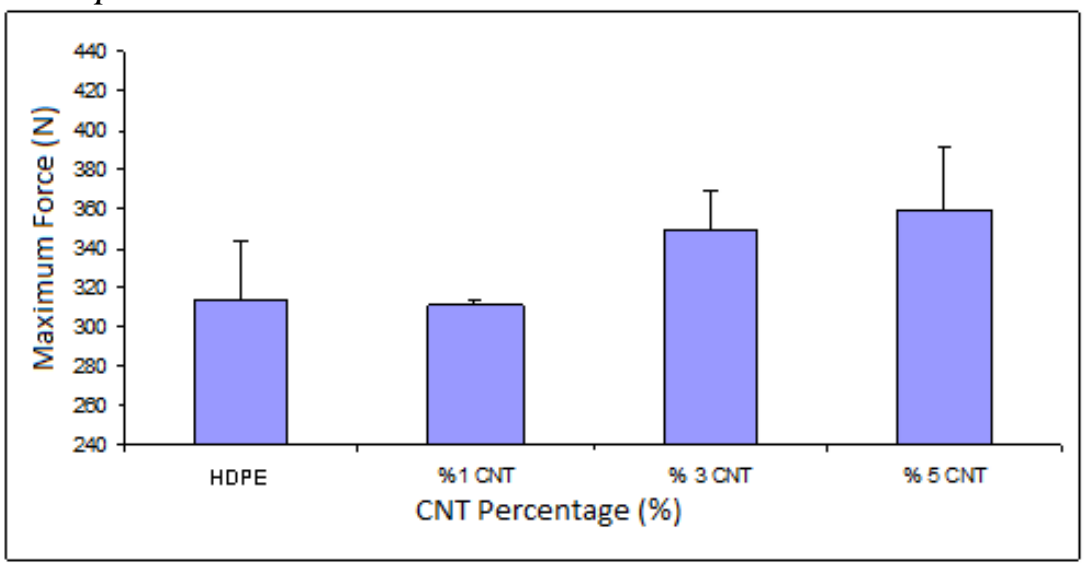

Figure 7. The Effect of MWCNT Reinforcement to Maximum Force at $66 \%$ Notched Samples

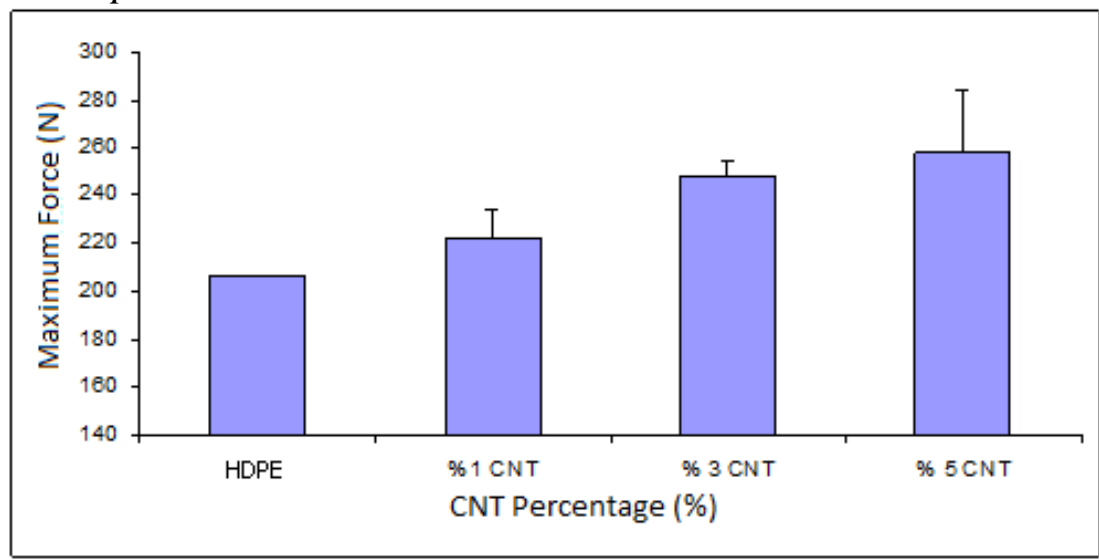

The results of elongation at break measurements and maximum stress of all samples are respectively presented in figures 8 . and 9. It is clear that reinforcement of MWCNTs has a negative effect on the elongation at break point. Elongations at break of all uncracked MWCNTs samples were found to decrease. Nanocomposite samples are seen to be more rigid. This case continues with the cracked edge sample at the rate of $0.25 \%$. However, the percentage decline is less. Percentage elongation at break of the cracked edge samples started to increase at the rate of $0.50 \%$ and $0.66 \%$ while MWCNT reinforcement is increasing. As a result of increasing length of edge cracks, percentage elongation at break of HDPE samples decreased more than that of the nanocomposites sample. This is evidence that MWCNT reinforcement exhibits a positive effect against cracks due to external influences.

While increasing ratio of edge cracks, damage began to resulting in opening crack instead of elongation of the sample. This situation has led to a decrease at the strength increase. In this way, percentage elongations at break of the nanocomposite samples tend to surpass those of the HDPE samples. 
During the tensile testing, increase in the proportion of edge cracks causes reduction of both tensile strength and elongation percentage. Mechanical properties showed that the tensile strength initially decreased or slightly increased with the increasing MWCNTs content. Subsequently, the tensile strength increased considerably with increasing MWCNTs content.

Accordingly, tensile-tensile fatigue tests will also be performed. These results show a high potential for increasing the fatigue life of plastics under mechanical load by the incorporation of carbon nanotubes in the matrix. Also, according to the results of the tensile test, fracture toughness can be calculated.

Figure 8. Elongation at Break

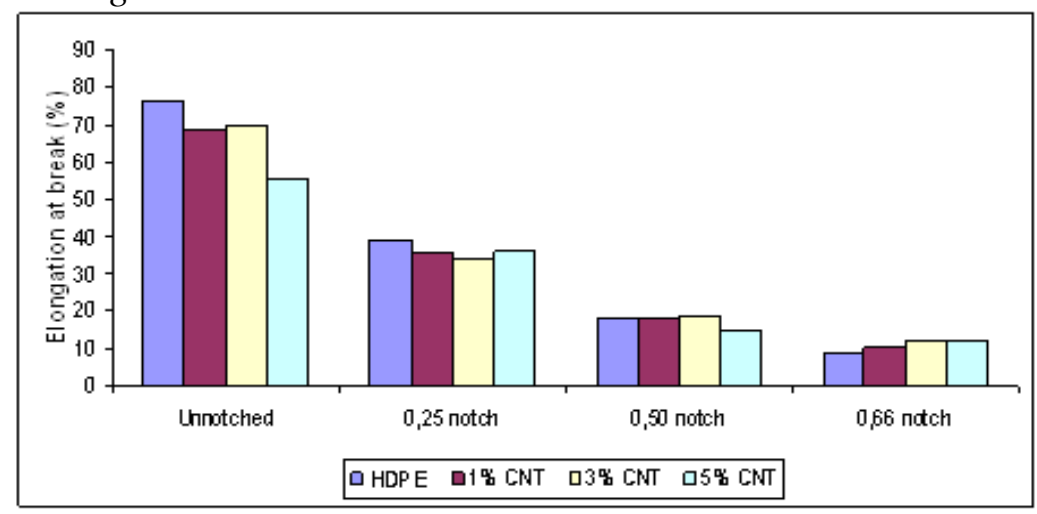

Figure 9. Maximum Stress of All Samples

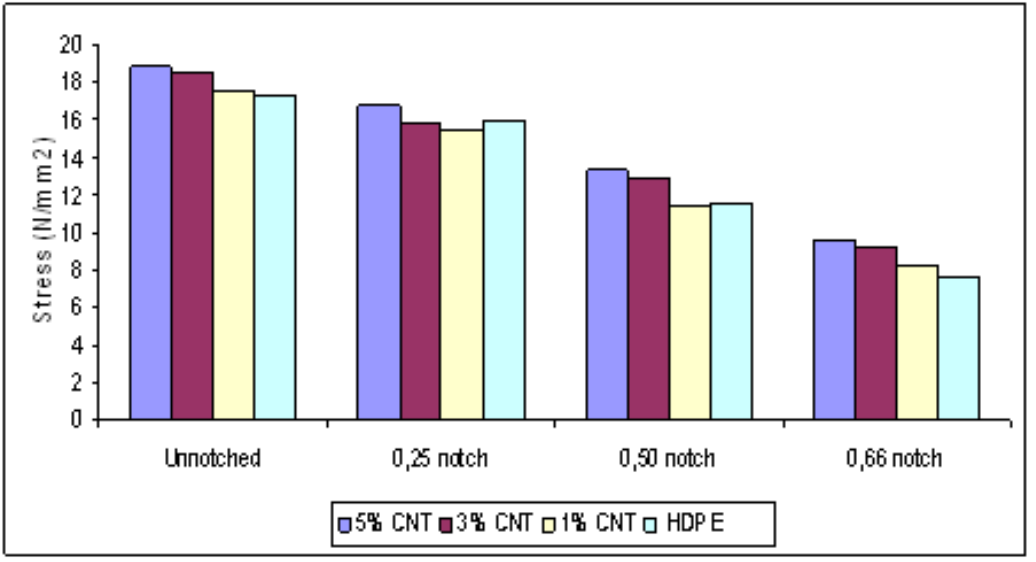

Also, stress intensity factor of single-edge cracked tensile test bars is shown in figure 10 . 
Figure 10. Stress Intensity Factor

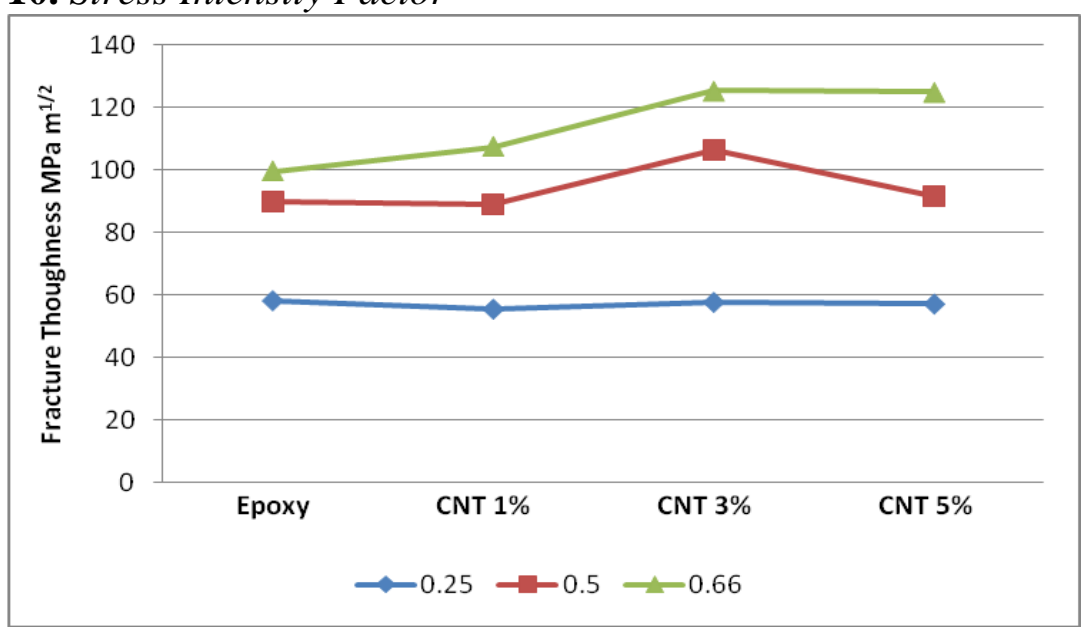

$T G A$

Normalized mass loss curves were measured by TGA for the MWCNTs nanocomposites and HDPE samples. TGA and DTG datas are respectively plotted in figures 11. and 12. TGA and DTG analysis showed that $T_{m}$ and $T_{c}$ increased very slightly in the HDPE/MWCNTs nanocomposite compared with those in HDPE. The thermal stability of nanocomposites has been improved because of the addition of MWCNTs. Besides that, the residual weight of HDPE/MWCNTs nanocomposites increased steadily with the increase of MWCNTs loading. As shown in figure 11., the mass loss midpoints of HDPE is $481.7^{\circ} \mathrm{C}$ and the mass loss midpoints of HDPE/MWCNTs $5 \% \mathrm{wt}$ is $489.07{ }^{\circ} \mathrm{C}$. This value is over $600{ }^{\circ} \mathrm{C}$ for MWCNT. Hence, mass loss occurs at higher temperatures as the MWCNT reinforcement ratio increase.

The analysis of thermal degradation in airflow showed a clear improvement of thermal stability for HDPE/MWCNTs nanocomposites, proportional to MWCNTs content.

Mass loss degradation temperature of the composite increases as the MWCNTs ratio increases according to the TGA data. The lowest mass loss rate value, according to the temperature, is for 3\% MWCNTs mass loss speed rate value. This shows that mass loss melting speed rate decreases with increasing MWCNTs weight ratio and melting point temperature increases. 
Figure 11. TGA Pattern

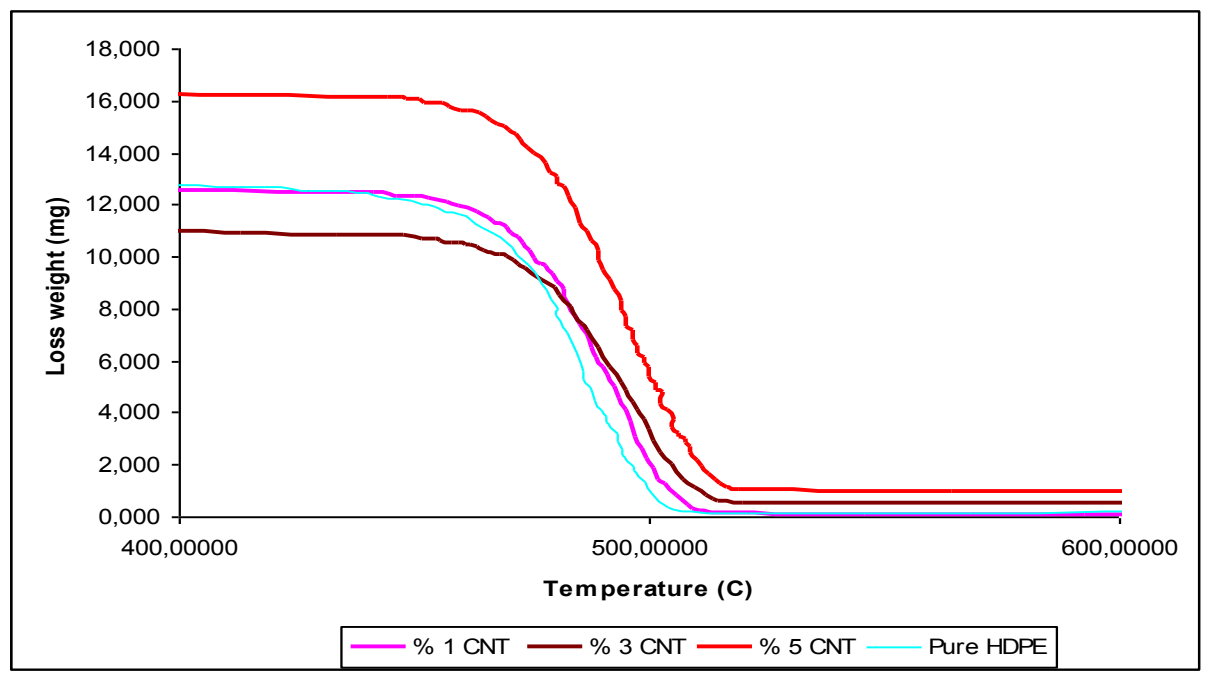

Figure 12. DTG Pattern

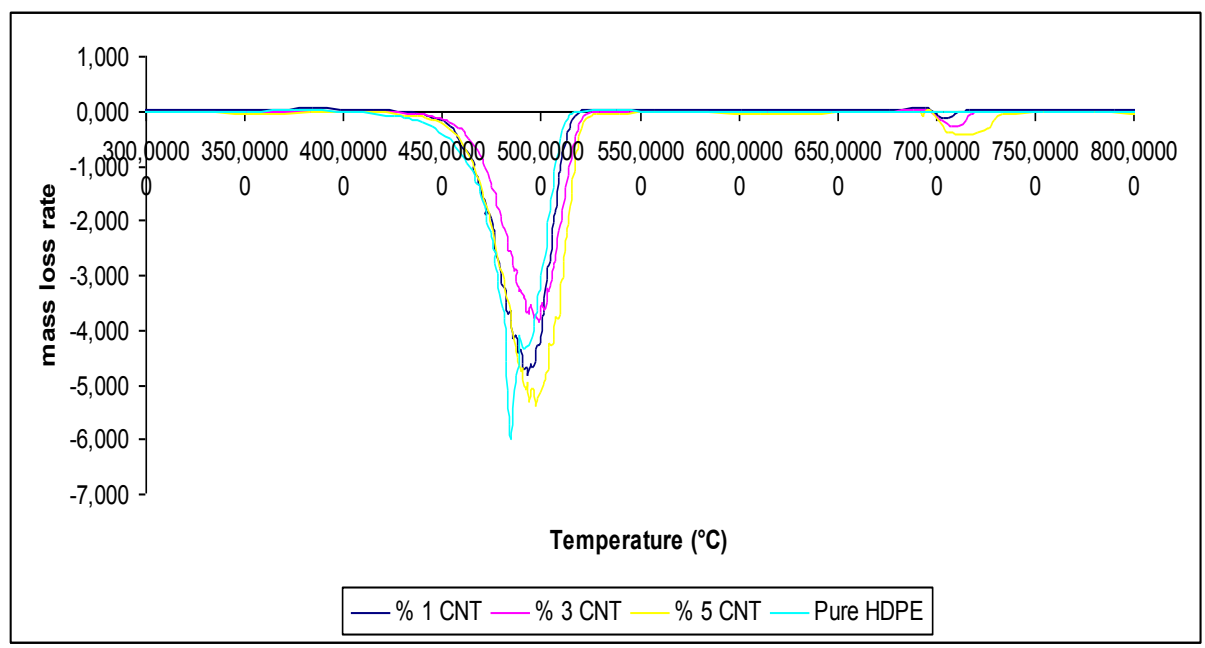

\section{Conclusions}

This study contains tensile strength tests of the MWCNT/HDPE composite specimens with various notch sizes. The study focuses on the improvement of mechanical properties of thermoplastic matrix reinforced with MWCNT.

The following conclusions are derived from the above reported studies:

1. Both the strength of notched HDPE specimens and the strength of notched MWCNT/HDPE composite specimens decreased with the increase of the notch length.

2. HDPE exhibits longer break extension lengths comparing to MWCNTs when uncracked samples are considered. However, break extension lengths of the nanocomposite samples became longer as the crack length increases. This value increased with increasing MWCNTs percentage. 
3. The static tensile strengths of MWCNT/HDPE composites were significantly enhanced by the addition of MWCNT. Namely, MWCNTs are good reinforcement material to improve the properties of HDPE.

4. Mass loss degradation temperature increased with increasing MWCNTs ratio.

\section{References}

Battisti, A., Skordos, A.A. and Partridge, I.K. (2009) Monitoring dispersion of carbon nanotubes in a thermosetting polyester resin, Composites Science and Technology. 69 (10). p.1516-1520. DOI: 10.1016/j.compscitech.2008.05.012

Dusunceli, N. and Colak, O.U. (2007) Impact of Manufacturing Methods on Uniaxial Tensile Behavior of High Density Polyethylene (HDPE). Proceedings of $8^{\text {th }}$ International Fracture Conference. İstanbul/TURKEY.

Gandhi, R.A. (2013) Role of carbon nanotubes (CNTs) in improving wear properties of polypropylene (PP) in dry sliding condition. Materials \& Design. 48. p.52-57 DOI: 10.1016/j.matdes.2012.08.081

Grimmer, C.S. and Dharan, C.K.H. (2010) Enhancement of delamination fatigue resistance in carbon nanotube reinforced glass fiber/polymer composites. Composites Science and Technology. 70. p.901-908 DOI: 10.1016/j.compscitech. 2010.02.001

Hooshmand, S., Soroudi, A. and Skrifvars, M. (2011) Electro-conductive composite fibers by melt spinning of polypropylene/polyamide/carbon nanotubes. Synthetic Metals. 161 (15-16). p.1731-1737. DOI: 10.1016/j.synthmet.2011.06.014

Jin-Hua, T. et al. (2012) Mechanical properties and thermal behaviour of LLDPE/ MWNTs nanocomposites. Materials Research, 15 (6). p.1050-1056. DOI: 10.1590/S1516-14392012005000122

Jung, C.H. et al. (2013) Fabrication and characterization of radiation-resistant LDPE/MWCNT nanocomposites. Journal of Nuclear Materials. 438 (1-3). p.4145. DOI: $10.1016 /$ j.radphyschem.2009.08.024

Kanagaraj, S. et al. (2007) Mechanical properties of high density polyethylene/carbon nanotube composites. Composites Science and Technology 67. p.3071-3077. DOI: $10.1016 /$ j.compscitech.2007.04.024

$\mathrm{Li}$, J. et al. (2006) Thermal degradation behavior of multi-walled carbon nanotubes/ polyamide 6 composites. Polymer Degradation and Stability. 91 (9). p.20462052. DOI: 10.1016/j.polymdegradstab.2006.02.001

Loos, M.R., Yang, J., Feke, D., L., Manas-Zloczower, I., Unal, S., Younes, U., (2013) Enhancement of fatigue life of polyurethane composites containing carbon nanotubes. Compozites: B 44. p.740-744. DOI: 10.1016/j.compositesb.2012. 01.038

Miannay, D.P. (1998) Linear elastic behaviour of flaws: Purely elastic treatment. Fracture mechanics, Mechanical Engineering Series, Chapter: 2 Springer. DOI 10.1007/978-1-4612-1740-4

Mirik, M. (2010) The Investigation of The Mechanical Properties of Carbon Nanotubes Reinforced High Density Polyethylene (HDPE) Nanocomposite Materials. The Graduate School of Natural and Applied Science of Selçuk University, Masters Thesis. Konya. 
Seyhan, A. et al. (2007) Rheological and dynamic-mechanical behavior of carbon nanotube/vinyl ester-polyester suspensions and their nanocomposites. European Polymer Journal. 43 (7). p.2836-2847. DOI: 10.1016/j.eurpolymj.2007.04.022

Tasyurek, M. (2012) Investigation Effect of Duration of Mixing to Material Strength in the MWCNT-Epoxy Nanocomposite Manufacturing Process. $14^{\text {th }}$ International Materials Symposium. Denizli/TURKEY.

Tasyurek, M. (2014) Investigation of Mechanical Properties And Fatigue Behavior Under Internal Pressure Effect of The $\pm 55^{\circ}$ Filament Winding CNT Reinforced CTP Composite Pipe With And Without Surface Crack. The Graduate School of Natural and Applied Science of Selçuk University, Ph.D Thesis. Konya.

Tasyurek, M. and Sepet, H. (2012) Mechanical Properties of Functionalized Multiwall Carbon Nanotubes/Epoxy Composites. $14^{\text {th }}$ International Materials Symposium. Denizli/TURKEY. 